\title{
ALL ON FOUR FIXED PROSTHESES VERSUS IMPLANT OVERDENTURES FOR MANAGEMENT OF EDENTULOUS MAXILLA OPPOSING MANDIBULAR 2- IMPLANT ASSISTED OVERDENTURES
}

\author{
Hesham Alam* and Mona Aboelnagga**
}

\begin{abstract}
Purpose: This study aimed to compare two treatment modalities; All on four fixed prostheses and locator retained overdentures; to rehabilitate patients having problems associated with edentulous maxilla opposing mandibular implant assisted overdentures.

Materials and methods: Ten patients complaining from looseness and instability of their maxillary dentures that oppose mandibular 2-implant-retained overdentures were randomly divided into 2 groups: Group I included 5 patients who received four implants according to the All-on- four Concept (2 parallel middle implants and 2 posterior implants with distal inclination). Implants were immediately loaded with fixed acrylic prosthesis, then after 6 months the prosthesis was replaced with fixed ceramometal restoration, Group II, included 5 patients who received four implants that were immediately loaded with Locator retained maxillary overdentures using new maxillary dentures. Clinical (plaque index (PI), gingival index (GI), probing depth (PD) and implant stability (IS)) and radiographic (marginal bone loss (MBL) outcomes were recorded at baseline (T0), 6 (T6) and 12 (T12) month after prosthesis insertion.
\end{abstract}

Results: PI, GI, PD, IS, and MBL increased significantly by time for the fixed prosthesis group. $\mathrm{PD}$, IS, and MBL increased significantly by time for the overdenture group. However no significant difference between observation times was noted for PI, and GI in the overdenture group. The fixed detachable prosthesis group recorded significant higher PI, GI, PD, and MBL than overdenture group after 6 (T6) and 12 month (T12) of prosthesis insertion.

Conclusion: Within the limitations of this short-term study, maxillary implant overdentures can be recommended to rehabilitate the edentulous maxilla opposed by implant assisted mandibular overdentures as it is associated with favorable clinical and radiographical outcomes compared to all on four fixed prostheses.

KEY WORDS: All on four, Implant assisted overdenture, Fixed detachable prosthesis, Locator attachment

* Associate Professor, Prosthonontic Department, Faculty of Oral and Dental Medicine at Future University ** Associate Professor, Prosthodontic Department, Faculty of Oral and Dental Medicine, and Shams University 


\section{INTRODUCTION}

Management of completely edentulous patients with two implants in the canine positions to assist mandibular overdentures was considered a routine prosthetic procedure ${ }^{1,2}$. Implant assisted mandibular overdenture has several advantages such as cost effectiveness, increased retention and stability of their conventional denture, increased patient satisfaction and oral health-related quality of life $^{3}$, improved chewing efficiency and bite force ${ }^{4}$, increased electromyographic muscle activity ${ }^{5}$, and minimal invasiveness in patients with compromised medical conditions.

Patients with 2-implant mandibular overdenture usually wear maxillary conventional dentures. The increased retention and stability of mandibular implant overdentures may cause several problems in the maxillary denture which are similar to the problems of combination syndrome ${ }^{6-8}$. Such problems include looseness and instability of the maxillary denture, maxillary anterior ridge resorption, flappy ridge at the anterior maxilla, palatal hyperplasia, and epulis fissuratum ${ }^{6-8}$. These problems usually resulted from increased occlusal pressure and bite force on the maxillary anterior ridge ${ }^{7-9}$. It was reported that there are increased maxillary bone loss and maxillary flabby ridges when maxillary complete denture was used against implant assisted mandibular overdentures with different types of attachments for 4 and 5 years ${ }^{9,10}$. The adequate solution for these problems is to provide optimum implant-support for the maxillary prosthesis in order to protect the maxillary ridge from these degenerative changes ${ }^{10}$.

Two major types of implant-supported prostheses can be used to restore edentulous maxilla; implantsupported overdentures and implant-supported fixed prosthesis. The choice between the two types depends on the implant position and their number, oral hygiene of the patient, cost of the procedures, patients' desire and aesthetic outcomes ${ }^{11}$. Fixed restoration is indicated with minimal bone loss, and it is associated with an increase in the cost and difficulty of managing prosthetic complications ${ }^{12}$. Implant overdentures are indicated with increased bone resorption to adequately restore the lip support, increased crown length, phonetics, class II and class III skeletal maxillomandibular relations ${ }^{13}$. Moreover, the prosthetic complications are easy to manage $^{14}$ and oral hygiene is easy to perform than the fixed restoration ${ }^{15}$.

Due to atrophy of the maxillary ridges and expansion of maxillary sinuses, insertion of four implants in the anterior maxillary region between the maxillary sinuses was considered in the last decade a viable treatment alternative to sinus augmentation and bone grafting procedures as it reduces patient morbidity, cost and time of the treatment ${ }^{16-18}$. The four implants are inserted parallel to each other and used to support maxillary overdentures with different attachments. Another treatment alternative is to insert the two posterior implants with $30^{\circ}$ distal inclination to support fixed prosthesis with immediate loading 'the All-on-4 implant concept' which was introduced by Malo et al. ${ }^{19}$ The All on 4 implant concept provides several merits such as; avoidance of invasive surgical procedures such as sinus augmentation and bone grafting, immediate loading of the implants (immediate restoration of function and esthetics in the same day of surgery using provisional restoration), reduction of distal cantilevers of the prosthesis and cost reduction ${ }^{19,20}$.

Reviewing the literature, the clinical outcomes ${ }^{21}$, bite force ${ }^{22}$, and patient satisfaction ${ }^{23}$ were evaluated for All-on 4 fixed restoration, in addition milled bar overdentures were used to rehabilitate the edentulous mandible opposed by conventional maxillary dentures. Also, Alrajhi et al. ${ }^{24}$ in a recent study, found that maxillary All on Four fixed prosthesis opposed by mandibular anterior teeth and distal extension mandibular partial dentures reduced maxillary bone resorption in the anterior and posterior areas compared to maxillary complete dentures. However, there is a lack of the studies comparing the clinical and radiographic 
outcomes of maxillary implant supported fixed prosthesis and overdentures opposing mandibular 2-implant assisted overdentures. Therefore, the aim of the present study was to evaluate clinical and radiographic outcomes of All on four fixed prostheses and implant assisted overdentures for management of edentulous maxilla opposing mandibular 2- implant assisted overdentures. The null hypothesis was that no difference in clinical and radiographic outcomes between the two procedures to be observed during one year follow up.

\section{MATERIALS AND METHODS}

\section{Patient cohort and study design}

In this study, a convenience sample of 10 patients (5 males and 5 females) were selected from outpatients clinic who were referred to the prosthodontic department for their persistent complaints regarding their maxillary dentures. The inclusion criteria of the participants are; 1) patients wearing maxillary conventional dentures and mandibular 2-implant-retained overdentures, and complained from looseness and instability of their maxillary dentures, 2) patients with sufficient restorative space for the maxillary prosthesis (at least $12 \mathrm{~mm}$ ) from the occlusal plane to the oral mucosa to accommodate either a fixed prosthesis or implant overdentures; this was assesed on mounted diagnostic casts using primiraly centric jaw relation, 3) sufficient amount of bone in the anterior maxilla between the maxillary sinuses allowing insertion of implants (at least $11 \mathrm{~mm}$ in length and $3.7 \mathrm{~mm}$ in diameter). This was verified by cone beam computerized tomography performed before surgery. (3) non-smokers and good oral hygine. The exclusion criteria included any medical conditions that compromise implant placement as liver, heart, autoimmune diseases, irradiated arches, and uncontrolled systemic or neurologic diseases.

All patients were informed about the treatment modality, and they signed an informed consent. The participants were randomly divided into two groups using the function of random numbers presented in the Microsoft Excel sheet. Allocation was performed to ensure equal gender distribution in each group. Group I included 5 patients who received four implants according to the All-on- four Concept ( 2 parallel anterior implants and 2 posterior implants with distal inclination). Implants were immediately loaded with fixed acrylic prosthesis, then after 6 months the prosthesis was replaced with fixed ceramometal restoration, Group II, included 5 patients who received four parallel implants that were immediately loaded with Locator retained maxillary overdentures.

\section{Surgical and prosthetic interventions}

For every patient, the old mandibular implant assissted over denture was evaluated and any needed adjustments was performed and new maxillary dentures were constructed with bilateral balanced occlusion. Radio-opaque gutta purcha markers were added to the buccal and palatal polished surfaces of their maxillary dentures. A dual scan protocol for each participant was made using cone beam computerized tomography while the patient wearing the maxillary and mandibular dentures and biting in cetric occlusion. A second separate scan was made for the maxillary denture alone. The two scans were overlapped on each other using a computer software (On Demand) to construct a three dimensional image for the edentulous maxilla. The bone height and width at the proposed implant sites for both groups was evaluated.

For group I, planing of implant position and orientation was performed using the All on 4 protocol $^{19}$. Four implants were inserted between the maxillary sinuses using the software (the anterior 2 implants were planned parallel to each other in canine or lateral incisor areas, while posterior 2 implants were inclined $30^{\circ}$ distally so that the abutment position would be in the first molar area). For group II, four implants were inserted parallel to each other in the area between the maxillary sinuses (the anterior two implants were inserted in the 
canine areas while the posterior two implants were inserted in the second premolar area bilateral).

The plan was used to construct for each patient a mucosa supported surgical guide using prototyping (laser sintering) technique. The guide was provided with metal rings over the implant sites into which metal sleeves of successive increasing diameter (corresponding to the drill diameters) can fit during osteotomy preparation. The guide and the computer guided surgical kit including sleeves and the drills were provided by the manufacture (In2guide company universal .kit cyber med, Seoul, Korea.)

At the surgical appointment, all patients administered prophylactic antibiotics (2 gm amoxicillin 1 hour before surgery) and mouth rinse $0.12 \%$ chlorhexidine digluconate (15 minutes prior to surgery). The surgical guide was fixed to the maxilla using fixation pins (fig1). For each patient, 4 implants (Neobiotech, South Korea) were installed using the surgical guide of the patient using flapless surgical approach.

For group I (All On Four fixed detachable restoration), multiunit abutments $\left(17^{\circ}\right.$ abutments for anterior implants and $30^{\circ}$ abutments for the posterior implants) with their temporary metal caps were connected to the implant fixtures immediately on the day of surgery and oriented properly so that the opening of the metal caps be on the occlusal surface

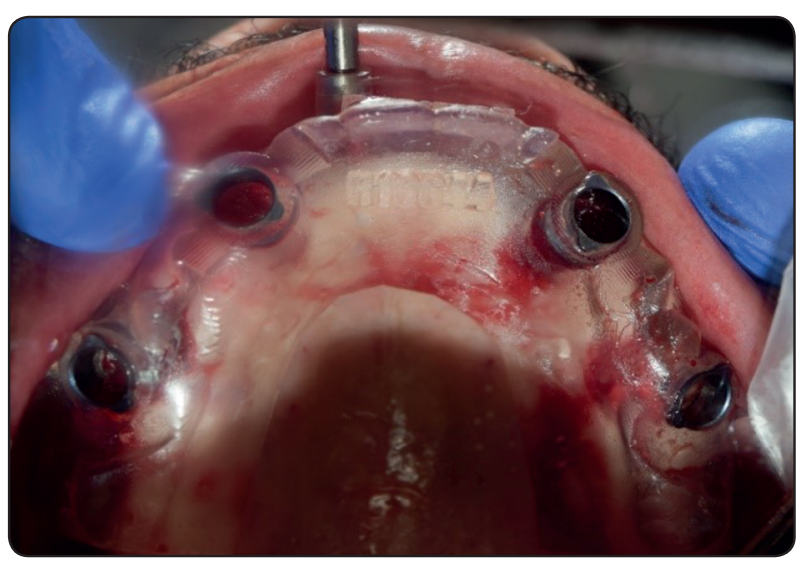

Fig. (1) Fixation of the guide into the maxillary bone using fixation pins. of the teeth. The maxillary denture was converted to fixed acrylic provisional restoration ${ }^{21,23,24}$ using the following steps; the dentures were hollowed over the metal caps, the buccal and palatal flanges of the dentures were removed, then pick up of the modified denture to the temporary metal caps was performed using self cure acrylic resin while the patient holding the modified maxillary denture and the mandibular overdenture in centric occlusion. The excess length of the metal caps were cut and excess acrylic resin was finished. The second molar artificial teeth were removed, and occlusion was relieved in the second premolar and first molar area to prevent overloading of the inclined implants, finally the dentures were screwed to the implants for immediate loading (fig 2).

For group II (overdentures), locator abutments (Neobiotech, South Korea) were screwed to the implants. White blocking rings were snapped onto the abutments, and the metal caps with processing inserts were placed over the abutments. The maxillary dentures were relieved opposing to the metal caps then the caps were picked up to the fitting surface of maxillary denture using self cure acrylic resin. The nylon inserts (blue, light retention) were placed in the metal housings (fig 3). The second molar artificial teeth were removed for standardization of occlusal scheme between the two groups. The dentures were finished, polished and delivered to the participants. Postoperative medications for all participants included: Antibiotics (Augmentin 625 $\mathrm{mg}$ ) and non-steroidal anti-inflammatory (Ibuprofen $400 \mathrm{mg}$ ) medications were given to the patients every 8 hours for 5 days postoperatively. All patients were limited to soft diet.

Aftersixmonthstoallowimplantosteointegration, for group I, the provisional restoration was replaced by fixed ceramometal restoration, and for group II, the maxillary overdenture was clinically evaluated and relining was made if needed. For group I, the provisional denture was unscrewed, Open tray impression posts were connected to the multiunit abutments and splinted with resin to avoid accidental 
movement during impression making. Abutment analogues were connected to the impression posts and the impression was poured. Plastic caps were connected to the abutments and fixed porcelain fused to metal restoration with 12 teeth (excluding second molar teeth) was waxed over the caps. The wax pattern was invested and casted in cobaltchromium alloy (Heraeus-Kulzer GmbH, Hanau, Germany) and tried in patient's mouth for passivity. Then, opaquer layer was added to the metal framework and porcelain powder was painted, fired, finished and glazed. Then the prosthesis was delivered to the participants after making the necessary occlusal adjustments (fig 3). For both groups, the patients were instructed in a plaque control protocol, and this was reinforced at subsequent follow up visits.
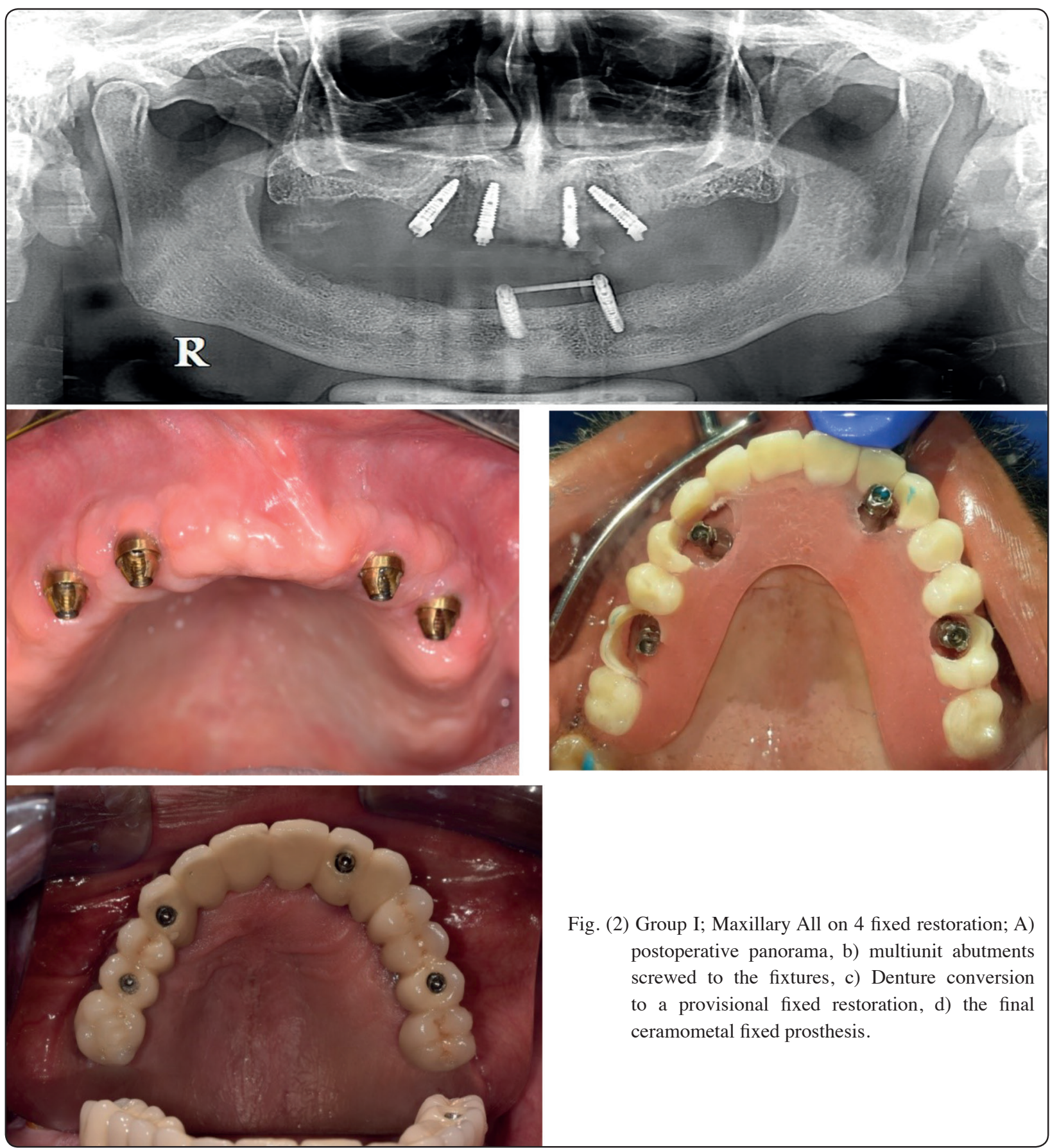

Fig. (2) Group I; Maxillary All on 4 fixed restoration; A) postoperative panorama, b) multiunit abutments screwed to the fixtures, c) Denture conversion to a provisional fixed restoration, d) the final ceramometal fixed prosthesis. 


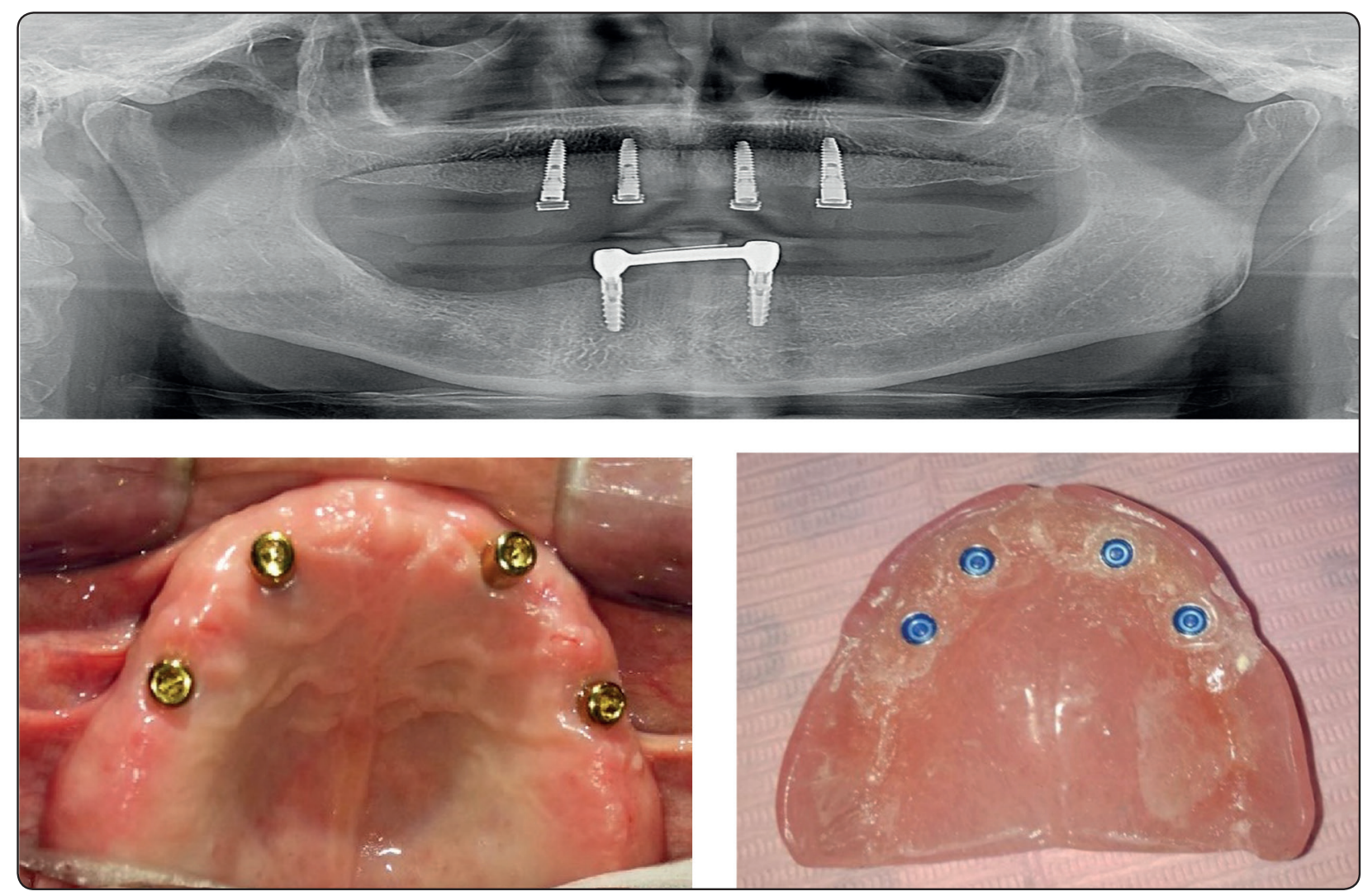

Fig. (3) Group 2; Maxillary implant overdentures; A) postoperative panorama, b) locator abutments screwed to the fixtures, c) nylon caps inserted in the metal housings.

\section{Clinical and radiographic evaluations}

Clinical and radiographic outcomes were recorded for each implant at time of immediate loading of the implants (T0, base line), 6 (T6) and 12 (T12) months after prosthesis insertion.

\section{(A) Clinical evaluation}

The following parameters were used to evaluate the clinical data

(1) Plaque Index $(\mathrm{PI})^{25}(0=$ no plaque; $1=$ plaque that can be detected by running a probe across the smooth marginal surface of the attachment and implant; 2 = plaque that is visible to the naked eye; 3 = abundant amounts of plaque).

(2) Gingival Index (GI) $)^{26}(0=$ normal peri-implant mucosa; 1 = mild inflammation, a slight change in color, and slight edema; 2 = moderate inflammation, redness, edema, and glazing; 3 $=$ severe inflammation, marked redness and edema, and ulceration).

(3) The probing depth (PD) was measured using a Williams periodontal probe as the distance between the marginal gingiva and the most apical depth of the probing. Plaque index, Gingival Index, and probing depths were evaluated after removal of the prosthesis at mesial, buccal, distal, and palatal surfaces of all implants.

(4) Implant stability (IS) was assessed by resonance frequency analysis (RFA, OsstellTM; Osstell AB, Gothenburg, Sweden) and expressed as ISQ (implant stability quotient) after attaching the SmartPegs to the implant 27, 28. The SmartPeg was threaded into the internal hex of the implant, and the handpiece of the device was held perpendicularly to the long axis of 
the SmartPeg. Measurements were performed three times and the mean was used for each implant. The mean readings of all implants were subjected to statistical analysis.

\section{(B) Radiographic evaluation}

Standardized long cone digital periapical radiographs were performed for each participant (Digora Optime, Orion Corp./Soredex). A personalized putty rubber base bite block was used to hold the plastic film holder Rinn- XCP (Rinn corp. Elgin, IL, USA) during subsequent exposures to standardize the film implant distance and the cone implant distance. The implant platform was used as the reference point (point A) (Fig 4). Evaluation of the marginal bone level around the implants was performed using image analysis software ${ }^{29}$. The distance between landmark A and the bone contact (B) was measured to indicate the level. Marginal bone loss (MBL) was calculated at mesial and distal aspects by subtracting the bone heights in the follow-up radiographs from those in the baseline radiographs. The mean MBL at mesial and distal aspects of all implants were averaged and the mean values for all implants were subjected to statistical analysis.

\section{Statistical analysis}

Shapiro Wilk Test of normality was used to detect the normal distribution of the data due to the small sample size included. The data were non-parametric. Categorical data (PI and GI) were expressed as median (min-max) and numerical data (PD, IS and MBL) were expressed as mean \pm standard deviation. Friedman test was used to compare different observation times and Wilcoxon signed ranks test was used to compare between the two times. Mann-Whitney test was used to compare data between groups, $P$ is significant at 0.05 level at confidence interval $95 \%$. The SPSS program statistical package for social science was used for data analysis.

\section{RESULTS}

Comparison of the clinical and radiographic outcomes between different observation times in both groups is shown in table 1 . There was a significant difference between observation times regarding all clinical and radiographic outcomes except plaque and gingival indices for overdenture group. PI, GI, PD, IS, and MBL increased significantly with time for the fixed detachable prosthesis group. PD, IS, and MBL increased significantly with time for the overdenture group. However no significant difference between observation times was noted for PI, and GI in the overdenture group.

Multiple comparisons between each two observation times for all clinical and radiographic parameters are presented in table 2. For both groups, there was a significant difference between

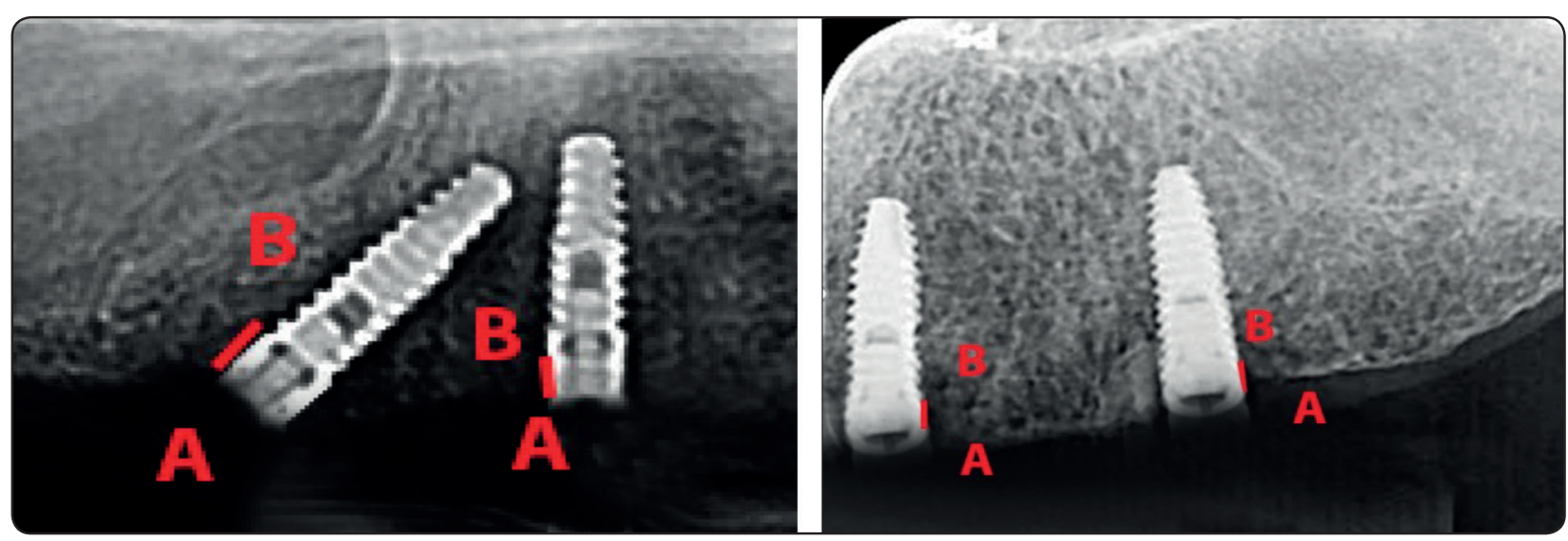

Fig. (4) Measurements of MBL for group I (a) and group II (b) 
TABLE (1): Comparison of clinical and radiographic outcomes between fixed detachable prosthesis and overdenture groups

\begin{tabular}{|c|c|c|c|c|}
\hline & $\begin{array}{l}\text { Base line } \\
\text { (T0) }\end{array}$ & $\begin{array}{c}6 \text { months after } \\
\text { prosthesis insertion (T6) }\end{array}$ & $\begin{array}{c}12 \text { months after } \\
\text { prosthesis insertion (T12) }\end{array}$ & $\begin{array}{l}\text { Freidman test } \\
\text { (p value) }\end{array}$ \\
\hline \multicolumn{5}{|c|}{ Plaque index (PI) } \\
\hline $\begin{array}{c}\text { Fixed detachable prosthesis } \\
\text { Me (min-max) }\end{array}$ & $.25(.00-1.0)$ & $1.5(1.0-2.0)$ & $2.5(1.5-3.0)$ & $.005^{*}$ \\
\hline $\begin{array}{l}\text { Overdentures } \\
\text { Me (min-max) }\end{array}$ & $.50(.00-1.0)$ & $.50(.00-1.0)$ & $1.0(.00-2.0)$ & .124 \\
\hline Mann-Whitney test & 1.00 & $.035^{*}$ & $.016^{*}$ & \\
\hline \multicolumn{5}{|c|}{ Gingiva index (GI) } \\
\hline \multicolumn{5}{|l|}{ Fixed } \\
\hline $\begin{array}{l}\text { detachable prosthesis } \\
\text { Me (min-max) }\end{array}$ & $.34(.00-1.0)$ & $1.25(0.5-1.5)$ & $2(1.00-3.0)$ & $.022 *$ \\
\hline $\begin{array}{l}\text { Overdentures } \\
\text { Me (min-max) }\end{array}$ & $.0(.00-1.0)$ & $.23(.50-1.0)$ & $1.0(.00-1.0)$ & .63 \\
\hline Mann-Whitney test & .62 & $.028 *$ & $.033^{*}$ & \\
\hline \multicolumn{5}{|c|}{ Probing depth (PD) } \\
\hline $\begin{array}{l}\text { Fixed detachable prosthesis } \\
\text { Mean } \pm \text { SD }\end{array}$ & $1.5 \pm .91$ & $2.5 \pm .82$ & $3.1 \pm 1.2$ & $.002 *$ \\
\hline Overdentures Mean \pm SD & $1.4 \pm .55$ & $1.8 \pm .85$ & $2.2 \pm .99$ & $.004 *$ \\
\hline Mann-Whitney test & .066 & $.029 *$ & $.043 *$ & \\
\hline \multicolumn{5}{|c|}{ Implant stability (IS) } \\
\hline $\begin{array}{c}\text { Fixed detachable } \\
\text { prosthesis Mean } \pm \text { SD }\end{array}$ & $65.4 \pm 4.7$ & $66.8 \pm 4.7$ & $68.5 \pm 4.9$ & $.035^{*}$ \\
\hline Overdentures Mean \pm SD & $66.9 \pm 5.1$ & $67.6 \pm 5.4$ & $69.1 \pm 5.2$ & $.030 *$ \\
\hline Mann-Whitney test & 68 & .72 & .44 & \\
\hline \multicolumn{5}{|c|}{ Marginal Bone loss (MBL) } \\
\hline $\begin{array}{l}\text { Fixed detachable prosthesis } \\
\text { Mean } \pm \text { SD }\end{array}$ & - & $1.3 \pm .35$ & $1.8 \pm .24$ & $.021^{*}$ \\
\hline Overdentures Mean \pm SD & - & $.76 \pm .38$ & $.92 \pm .31$ & $.013 *$ \\
\hline Mann-Whitney test & - & $.007 *$ & $.038 *$ & \\
\hline
\end{tabular}

Me: median, min: minimum, max: maximum, SD: standard deviation. *: P value significant at .05 
T6 and T12 and between T0 and T12 for PI and GI. There was a significant difference between each two-time intervals for PD and IS in both groups. MBL increased significantly from T6 to T12 in both groups.

TABLE (2): Multiple comparisons between each 2-time intervals for fixed detachable prosthesis and overdentures. Number in each cell shows $\mathrm{P}$ values of Wilcoxon sign ranks test

\begin{tabular}{|c|c|c|c|}
\hline & $\begin{array}{c}\text { Base line } \\
\text { (T12) }\end{array}$ & $\begin{array}{c}\text { Base line (T0)- } \\
\text { (T0)- } 612 \\
\text { months (T6) }\end{array}$ & $\begin{array}{c}6 \text { months } \\
\text { (T6) -12 } \\
\text { months (T12) }\end{array}$ \\
\hline \multicolumn{4}{|c|}{ Plaque index (PI) } \\
\hline $\begin{array}{c}\text { Fixed detachable } \\
\text { prosthesis }\end{array}$ & .57 & $.003 *$ & $.015^{*}$ \\
\hline Overdentures & .49 & .25 & .37 \\
\hline \multicolumn{4}{|c|}{ Gingival index (GI) } \\
\hline $\begin{array}{c}\text { Fixed detachable } \\
\text { prosthesis }\end{array}$ & .77 & $.048 *$ & $.025 *$ \\
\hline Overdentures & .38 & .16 & .13 \\
\hline \multicolumn{4}{|c|}{ Probing depth (PD) } \\
\hline $\begin{array}{c}\text { Fixed detachable } \\
\text { prosthesis }\end{array}$ & $.035^{*}$ & $.028 *$ & $.032 *$ \\
\hline Overdentures & $.025^{*}$ & $.015^{*}$ & $.035^{*}$ \\
\hline \multicolumn{4}{|c|}{ Implant stability (IS) } \\
\hline $\begin{array}{c}\text { Fixed detachable } \\
\text { prosthesis }\end{array}$ & $.039 *$ & $.026 *$ & $.017 *$ \\
\hline Overdentures & $.017 *$ & $.044 *$ & $.042 *$ \\
\hline \multicolumn{4}{|c|}{ Marginal Bone loss (MBL) } \\
\hline $\begin{array}{c}\text { Fixed detachable } \\
\text { prosthesis }\end{array}$ & - & - & $.021 *$ \\
\hline Overdentures & - & - & $.013^{*}$ \\
\hline
\end{tabular}

$P$ is significant at $5 \%$

Comparison of clinical and radiographic outcomes between fixed detachable and overdenture groups is shown in table1. For all clinical and radiographic parameters (PI, GI, PD, IS), there was no significant difference between groups at baseline (T0). The fixed detachable prosthesis group recorded significant higher PI, GI, PD, and MBL than overdenture group after six (T6) and 12 months (T12) of prosthesis insertion. No significant difference in IS between groups was after six (T6) and 12 months (T12) of prosthesis insertion.

\section{DISCUSSION}

In this study, PI and GI increased significantly with time for the fixed detachable prosthesis group. However no significant difference between observation time was noted for PI, and GI in the overdenture group. The increased PI with time, although the given oral hygiene instructions, in the fixed detachable group may be attributed to the inadequate cleaning of the prosthesis by the patients due to inability to remove the prosthesis and the decreased manual dexterity due to advanced age of the patients. The ability to remove the overdenture prosthesis for cleaning may be responsible for the lack of increase in PI with time. Similarly, MericskeStern, et al ${ }^{30}$ found an evidence of healthy periimplant soft tissues under maxillary overdentures with insignificant increase in PI and GI parameters.

The increased PI with time is the main cause for increasing GI as plaque accumulation is usually associated with the implant mucosal irritation and inflammation. The causal relation between plaque and gingival inflammation was previously reported ${ }^{31}$. The fixed detachable prosthesis group recorded significant higher PI, GI compared to overdentures group, this may be due to increased plaque adherence to the fitting surface of the prosthesis around the rough metal cylinders of the multiunit abutments and inability to remove the prosthesis to perform adequate oral hygiene. Conversely, the unsplinted (locator) attachment in the overdenture group has smooth surface which enhance cleaning and performing oral hygiene as 
they are more hygienic and self-cleansing ${ }^{32}$. The reduced PI and GI with locators are in agreement with other studies ${ }^{33}, 34$ in which they reported reduced PI and GI with locator retained maxillary overdentures.

Pocket depth increased with time in both groups. This could be attributed to the increased marginal bone loss in both groups together with increased thickness of peri-implant keratinized mucosa. The increased probing depth with fixed prosthesis group is in line with a previous study for All-on-4 prosthesis in the mandibular $\operatorname{arch}^{21}$. Also the increased probing depth in the overdenture group concurred with the study of Cordaro, et al. ${ }^{35}$ which was conducted on locator retained maxillary overdentures. However, the fixed detachable prosthesis group reported significant higher PD than the overdenture group. This could be attributed to the increased marginal bone loss in the fixed detachable group compared to overdenture group. Moreover, the increased gingival inflammation in the fixed detachable group may cause gingival proliferation around the metal cylinders of the prosthesis and could be responsible for increased probing depth. On the other hand, peri-implant mucosal recession may occur in overdenture group due to the repeated insertions and removals of the prosthesis and could be responsible for decreasing probing depth.

Resonance frequency analysis measurements have been used to document changes during healing of the implant-bone interface ${ }^{36,37}$. ISQ values more than 65 are considered as most favorable for implant stability which is an essential requirement for immediate loading. ${ }^{38}$ An increase in IS is related to an increase in the stiffness of the interface between the implant and the surrounding bone ${ }^{27}$. In both groups, the increased IS with time could be a direct result of increased bone density and bone to implant contact with passage of time after loading which increases anchorage and stiffness of the implants in the soft maxillary bone ${ }^{27}$. In line with this explanation, Chen ${ }^{39}$ who found a significant increase in IS values of maxillary implants from baseline to one year after loading. However, the implant stability did not significantly differ between the fixed detachable prosthesis and the overdenture groups.

The amount of MBL after one-year for the fixed detachable prosthesis group $(1.8 \pm .24)$ was higher than the normal amount of marginal bone loss reported in the literature which is $1.2 \mathrm{~mm}$ in the first year after prosthesis loading. ${ }^{40}$ The increased amount of MBL in the fixed detachable group concurred with the results of Browaeys et al. ${ }^{41}$ who reported that patients rehabilitated with All-on-4 fixed prosthesis had unacceptable ongoing bone loss seen in $49.2 \%$ of the patients. From this observation, the increased bone loss in the first year should be considered an alarming sign for possibility of future increase in marginal bone loss that requires clinical attention. Therefore, it may be recommended to insert six implants (using the All on 6 protocol) to support fixed prosthesis subjected to immediate loading in edentulous maxilla opposed by mandibular implant overdentures to preserve the marginal bone on longer-term perspectives. However, it should be noted that the total amount of bone resorption recorded included bone resorption that occurred in the healing period after immediate loading which is usually overlooked and was not calculated in several studies, as the treatment modalities are compared as a whole.

MBL increased significantly with time for the fixed detachable prosthesis and overdentures group. A similar observation was noted in another study ${ }^{42}$ for all on 4 fixed restoration and for Locator maxillary overdentures ${ }^{33,43}$ and could be attributed to bone reaction to surgical trauma and occlusal loading. The increased MBL in both groups may be due to the occlusal load that is transmitted to palatally inclined implants where these implants have to be inserted with palatal inclination 
due to the anatomical shape of the premaxilla. The implant inclination was associated with greater strain and marginal bone loss than the vertical oriented ones ${ }^{44}$. Moreover, the reduced bone quality of maxilla contributes to more MBL than mandibular bone ${ }^{45,46}$. Also, the habitual protrusion of the mandible by the patients due to presence of mandibular implants may increase occlusal force transmission to the maxillary implants and could be responsible for increasing MBL with time. Furthermore, the immediate loading protocol used in both groups which may result in increased micromotions at implant/ bone interface thus interfering with the healing process and may be responsible for the increased $\mathrm{MBL}^{47}$.

The fixed detachable prosthesis group recorded significant higher MBL than overdenture group. This could be attributed to the presence of a distal inclined posterior implants in the fixed detachable prosthesis group compared to axial implants in the overdenture group which may increase implant overloading and could be responsible for the increase in the marginal bone loss. In an in-vitro photoelastic stress analysis study, implants with distal inclination that are used to support fixed prosthesis were more prone to occlusal overload than vertical implants ${ }^{48}$. However, in another clinical study tilting of the implants did not seem to result in differences in peri-implant bone level compared with the upright implants ${ }^{41}$.

Another explanation for increased bone loss in the fixed detachable group may be attributed to the increased amount of biting force. Fürhauser et al ${ }^{22}$ found that patients rehabilitated with fixed implant (All- on- 4 technique) showed bite forces similar to or even more than full dentate patients. On the other hand that patients wearing complete dentures, single implant assisted overdentures or implant supported bridges showed a reduction of bite force by $53 \% .{ }^{22}$ Most probably that the patient get more confident with the fixed prosthesis and apply more biting force that may lead to implant overloading with subsequent increased MBL.

On the other hand, the reduced bone loss in the overdenture group may be attributed to the resiliency of locator attachments which absorb the occlusal load as locator attachments permit vertical movement of the prosthesis together with limited hinge movement due to the resiliency of nylon inserts ${ }^{49,50}$. Moreover, locators have reduced occlusal height compared to increased crown length in the fixed detachable prosthesis group. This reduces the vertical cantilever of the prosthesis and could be responsible for reduced bone loss in the overdenture group. In addition, the load in the overdenture group is shared between the implants, the ridge and the palate and consequently the tissue support reduced load transmission to the implants where more stress distribution.

The limitations of this study are the reduced patient sample and the short term follow up period. Therefore, longer-term randomized controlled trials with sufficient sample size are needed to confirm the results of this clinical study.

\section{CONCLUSION}

Within the limitations of this study, maxillary implant overdentures can be recommended to rehabilitate the edentulous maxilla opposed by implant assisted mandibular overdentures as it is associated with favorable clinical and radiographic outcomes compared to All on four fixed prosthesis

\section{REFERENCES}

1. Feine JS, Carlsson GE, Awad MA, Chehade A, Duncan WJ, Gizani S, Head T, Heydecke G, Lund JP, MacEntee M, Mericske-Stern R, Mojon P, Morais JA, Naert I, Payne AG, Penrod J, Stoker GT, Tawse-Smith A, Taylor TD, Thomason JM, Thomson WM, Wismeijer D. The McGill consensus statement on overdentures. Mandibular twoimplant overdentures as first choice standard of care for edentulous patients. Gerodontology 2002; 19: 3-4. 
2. Thomason JM, Feine J, Exley C, Moynihan P, Muller F, Naert I, Ellis JS, Barclay C, Butterworth C, Scott B, Lynch C, Stewardson D, Smith P, Welfare R, Hyde P, McAndrew R, Fenlon M, Barclay S, Barker D. Mandibular two implantsupported overdentures as the first choice standard of care for edentulous patients--the York Consensus Statement. Br Dent J 2009; 207: 185-186.

3. Mishraa SK, Chowdhary R. Patient's oral health-related quality of life and satisfaction with implant supported overdentures -a systematic review. Journal of Oral Biology and Craniofacial Research 2019; 9(4): 340-346.

4. Sharma AJ, Nagrath R, Lahori M. A comparative evaluation of chewing efficiency, masticatory bite force, and patient satisfaction between conventional denture and implantsupported mandibular overdenture: An in vivo study. J Indian Prosthodont Soc. 2017 OctDec; 17(4): 361-372.

5. Karkazis HC. EMG activity of the masseter muscle in implant supported overdenture wearers during chewing of hard and soft food. J of Oral Rehabil 2002; 29(10): 986-991.

6. Barber HD, Scott RF, Maxson BB, Fonseca RJ. Evaluation of anterior maxillary alveolar ridge resorption when opposed by the transmandibular implant. J Oral Maxillofac Surg 1990; 48: 1283-1287.

7. Lechner SK, Mammen A. Combination syndrome in relation to osseointegrated implantsupported overdentures: a survey. Int J Prosthodont 1996; 9: 58-64.

8. Thiel CP, Evans DB, Burnett RR. Combination syndrome associated with a mandibular implant-supported overdenture: a clinical report. J Prosthet Dent 1996; 75: 107-113.

9. Maxson BB, Powers MP, Scott RF. Prosthodontic considerations for the transmandibular implant. J Prosthet Dent 1990; 63: 554-558.

10. Tolstunov L. Combination syndrome: classification and case report. J Oral Implantol 2007; 33: 139-151

11. Payne GT, Zarb G. Prosthodontic Treatment for Edentulous Patients: Complete Dentures and ImplantSupported Prosthesis. In: Zarb GA BC, Eckert S, Jacob R, Fenton A, MericskeSterns, ed. Proceedings of the Implant overdentures.: Mosby, 2013: 330-339.

12. Beikler T, Flemmig TF. EAO consensus conference: economic evaluation of implantsupported prostheses. Clin Oral Implants Res 2015; 26 Suppl 11: 57-63.
13. D Mericske, Stern R, Taylor TD, Belser U. Management of the edentulous patient. Clinical Oral Implants Research 2000; 11: 108-125.

14. Katsoulis J, Brunner A, Mericske-Stern R. Maintenance of implant-supported maxillary prostheses: a 2-year controlled clinical trial. Int J Oral Maxillofac Implants 2011; 26: 648656.

15. Naert I, Gizani S, van Steenberghe D. Rigidly splinted implants in the resorbed maxilla to retain a hinging overdenture: a series of clinical reports for up to 4 years. J Prosthet Dent 1998; 79: 156-164.

16. Stellingsma C, Vissink A, Meijer HJ, Kuiper C, Raghoebar GM. Implantology and the severely resorbed edentulous mandible. Crit Rev Oral Biol Med 2004; 15: 240-248.

17. Stellingsma K, Raghoebar GM, Meijer HJ, Stegenga B. The extremely resorbed mandible: a comparative prospective study of 2-year results with 3 treatment strategies. Int J Oral Maxillofac Implants 2004; 19: 563-577.

18. Krekmanov L, Kahn M, Rangert B, Lindstrom H. Tilting of posterior mandibular and maxillary implants for improved prosthesis support. Int J Oral Maxillofac Implants 2000; 15: 405-414.

19. Maló P, Rangert B, Nobre M.All-on-4 immediate-function concept with Brånemark System implants for completely edentulous maxillae: a 1-year retrospective clinical study. Clin Implant Dent Relat Res 2005; 7 Suppl 1: S88-S94.

20. Malo P, de Araujo Nobre M, Lopes A, Francischone C, Rigolizzo M. "All-on-4" immediatefunction concept for completely edentulous maxillae: a clinical report on the medium (3 years) and long-term (5 years) outcomes. Clin Implant Dent Relat Res 2012; 14 Suppl 1: e139-150.

21. ElSyad MA, Alameldeen HE, Elsaih EA. Four-implantsupported fixed prosthesis and milled bar overdentures for rehabilitation of the edentulous mandible: A 1-year randomized controlled clinical and radiographic study. Int $\mathrm{J}$ Oral Maxillofac Implants 2019; 34: 14931503.

22. Fürhauser N, Busenlechner D, Haas R, Millesi W, Fürhauser R, Mailath-Pokorny G, Pommer B. Bite force after fixed full- arch implant rehabilitation (all- on- 4) compared to complete dentures and dentate patients. Clin Oral Impl Res. 2018; 29(17): 365.

23. ELsyad MA, Elgamal M, Mohammed Askar O, Youssef AlTonbary G. Patient satisfaction and oral health-related quality of life (OHRQoL) of conventional denture, fixed prosthesis 
and milled bar overdenture for All-on-4 implant rehabilitation. A crossover study. Clin Oral Implants Res 2019.

24. Alrajhi MS, Askar O, Habib AA, Elsyad MA. Maxillary Bone Resorption with Conventional Dentures and FourImplant-Supported Fixed Prosthesis Opposed by DistalExtension Partial Dentures: A Preliminary 5-year Retrospective Study. Int J Oral Maxillofac Implants 2020; 35: 816-823.

25. Mombelli A, van Oosten MA, Schurch E, Jr., Land NP. The microbiota associated with successful or failing osseointegrated titanium implants. Oral Microbiol Immunol 1987; 2: 145-151.

26. Loe H, Silness J. Periodontal Disease in Pregnancy. I. Prevalence and Severity. Acta Odontol Scand 1963; 21: 533-551.

27. Meredith N, Alleyne D, Cawley P. Quantitative determination of the stability of the implanttissue interface using resonance frequency analysis. Clin Oral Implants Res 1996; 7: 261267.

28. Glauser R, Sennerby L, Meredith N, Ree A, Lundgren A, Gottlow J, Hammerle CH. Resonance frequency analysis of implants subjected to immediate or early functional occlusal loading. Successful vs. failing implants. Clin Oral Implants Res 2004; 15: 428-434.

29. Canullo L, Fedele GR, Iannello G, Jepsen S. Platform switching and marginal bone-level alterations: the results of a randomized-controlled trial. Clin Oral Implants Res 2010; 21: 115-121.

30. Mericske-Stern R, Oetterli M, Kiener P, Mericske E. A follow-up study of maxillary implants supporting an overdenture: clinical and radiographic results. Int J Oral Maxillofac Implants 2002; 17: 678-686.

31. Malo P, de Araujo Nobre M, Moura Guedes C, Almeida R, Silva A, Sereno N, Legatheaux J. Short-term report of an ongoing prospective cohort study evaluating the outcome of full-arch implant-supported fixed hybrid polyetheretherketone-acrylic resin prostheses and the All-onFour concept. Clin Implant Dent Relat Res 2018; 20: 692-702.

32. Kleis WK, Kammerer PW, Hartmann S, Al-Nawas B, Wagner W. A comparison of three different attachment systems for mandibular two-implant overdentures: one-year report. Clin Implant Dent Relat Res 2010; 12: 209-218.

33. Bouhy A, Rompen E, Lamy M, Legros C, Lecloux G, Lambert F. Maxillary implant overdenture retained by four unsplinted attachments and opposed by a natural or fixed dentition: One-year clinical outcomes. Clin Oral Implants Res 2020; 31: 747-767.

34. Boven GC, Meijer HJA, Vissink A, Raghoebar GM. Maxillary implant overdentures retained by use of bars or locator attachments: 1-year findings from a randomized controlled trial. J Prosthodont Res 2019.

35. Cordaro L, Torsello F, Mirisola di Torresanto V, Baricevic M. Rehabilitation of an edentulous atrophic maxilla with four unsplinted narrow diameter titanium-zirconium implants supporting an overdenture. Quintessence Int 2013; 44: 37-43.

36. Barewal RM, Oates TW, Meredith N, Cochran DL. Resonance frequency measurement of implant stability in vivo on implants with a sandblasted and acid-etched surface. Int J Oral Maxillofac Implants 2003; 18: 641-651.

37. Friberg B, Sennerby L, Linden B, Grondahl K, Lekholm U. Stability measurements of onestage Branemark implants during healing in mandibles. A clinical resonance frequency analysis study. Int J Oral Maxillofac Surg 1999; 28: 266-272.

38. Ramakrishna R, Nayar S. Clinical assessment of primary stability of endosseous implants placed in the incisor region, using resonance frequency analysis methodology: An in vivo study. Indian J Dent Res. 2007;18:168-172.

39. Chen MH, Lyons K, Tawse-Smith A, Ma S. Resonance Frequency Analysis in Assessing Implant Stability: A Retrospective Analysis. Int J Prosthodont 2019; 32: 317-326.

40. Albrektsson T, Zarb G, Worthington P, Eriksson AR. The long-term efficacy of currently used dental implants: a review and proposed criteria of success. Int J Oral Maxillofac Implants 1986; 1: 11-25.

41. Browaeys H, Dierens M, Ruyffelaert C, Matthijs C, De Bruyn H, Vandeweghe S. Ongoing Crestal Bone Loss around Implants Subjected to Computer-Guided Flapless Surgery and Immediate Loading Using the All-on-4(R) Concept. Clin Implant Dent Relat Res 2015; 17: 831-843.

42. Krennmair S, Weinländer M, Malek M, Forstner T, Krennmair G, Stimmelmayr M. Mandibular Full-Arch Fixed Prostheses Supported on 4 Implants with Either Axial Or Tilted Distal Implants: A 3-Year Prospective Study. Clinical Implant Dentistry and Related Research 2016; 18 : 1119-1133.

43. Boven GC, Meijer HJA, Vissink A, Raghoebar GM. Maxillary implant overdentures retained by use of bars or 
locator attachments: 1-year findings from a randomized controlled trial. J Prosthodont Res 2020; 64: 26-33.

44. Elsyad MA, Abid KS, Elkhalek EA. Effect of Buccal Implant Inclination on Stresses Around Two-ImplantRetained Overdentures with Resilient Stud Attachments. Int J Oral Maxillofac Implants 2017; 32: e135-e142.

45. Rodriguez AM, Orenstein IH, Morris HF, Ochi S. Survival of various implant-supported prosthesis designs following 36 months of clinical function. Ann Periodontol 2000; 5: 101108

46. ELsyad MA, Ghoneem NE, El-Sharkawy H. Marginal bone loss around unsplinted miniimplants supporting maxillary overdentures: a preliminary comparative study between partial and full palatal coverage. Quintessence Int 2013; 44: 45-52.
47. Romanos GE, Nentwig GH. Immediate versus delayed functional loading of implants in the posterior mandible: a 2-year prospective clinical study of 12 consecutive cases. Int J Periodontics Restorative Dent 2006; 26: 459-469.

48. Begg T, Geerts GA, Gryzagoridis J. Stress patterns around distal angled implants in the allon-four concept configuration. Int J Oral Maxillofac Implants 2009; 24: 663-671.

49. Chikunov I, Doan P, Vahidi F. Implant-retained partial overdenture with resilient attachments. J Prosthodont 2008; 17: 141-148.

50. Lee CK, Agar JR. Surgical and prosthetic planning for a two-implant-retained mandibular overdenture: a clinical report. J Prosthet Dent 2006; 95: 102-105. 